\title{
Negotiating the Confluence: Middle-Eastern, Immigrant, Sexual-Minority Men and Concerns for Learning and Identity
}

\author{
Matthew A. Eichler \\ Texas State University-San Marcos \\ Robert C. Mizzi \\ University of Manitoba
}

\begin{abstract}
Sexual-minority male immigrants re-locating from the Middle East to the United States and Canada have particular experiences upon entry and integration into their new societies. The needs of learning and identity are highlighted through a multiple case approach involving three men. Interviews were conducted with the three participants, which were analyzed by the authors using qualitative case analysis. The data highlights the unmet expectations for life as a new immigrant, as well as the complexities of becoming involved in sexual-minority settings. Their learning experiences may be explained using a theoretical framework of transformative learning. These findings suggest that sexual-minority immigrants have complex needs, such as identifying with appropriate communities and deconstructing false representations of "gay rights" and citizenship in popular culture. Educational and social programs could address these needs when considering what might be important for immigrant adult learners.
\end{abstract}

Key words: homosexuality, adult education, transformative learning, immigration

Matthew A. Eichler is an assistant professor in the Department of Occupational, Workforce, and Leadership Studies at Texas State University-San Marcos (USA). He teaches online and blended courses in interdisciplinary research methods and career and technical education for working adults. His research interests include learning in lesbian, gay, bisexual, transgender, queer and ally movements; interdisciplinary adult students as complex problem solvers; and social issues in distance learning.

Robert C. Mizzi, Ph.D., is an Assistant Professor in the Faculty of Education at the University of Manitoba. His research interests include sexuality and gender issues in education; educators who cross borders for work purposes; and studies of professional regulation.

Brock Education Volume 22, No. 2, Spring 2013, pp. 84-98 


\section{Introduction}

Sexual-minority ${ }^{1}$ males immigrate to developed ${ }^{2}$ nations from less developed nations for a variety of reasons. We hold that sexual-minority males that immigrate to the United States and Canada from Islamic Middle Eastern countries are a group largely hidden in scholarship on sexual-minorities and mobility. This is a study of three immigrants who face the challenges of integrating into life in the United States and Canada as sexual-minorities. The cases, in part, point out the degree to which North American and sexual-minority culture are hospitable to sexual-minority male immigrants from the Middle East. Immigration is often characterized by complex bureaucratic systems that are designed to make the complex process labour intensive, expensive and difficult (Epps, Valens, \& González, 2005). This means that although some sexual-minority males will be able to successfully cross borders, most applicants cannot due to the complexity. For sexual-minority males in particular, this process becomes increasingly difficult because they must determine whether identifying as a sexual-minority male through, for example, describing their same-sex partnership status on an application form, will negatively affect their application due to the pervasive nature of homophobia.

Keeping in mind this context, the purpose of this paper is to explore the lives of Middle Eastern, sexual-minority, male immigrants to the United States and Canada. Our use of the term immigrant is not without awareness of the political ramifications. Within the Canadian context, the term immigrant has two distinctive definitions in the literature: (a) a "transitional category" that refers to individual being admitted into one country and yet have not received citizenship and (b) a "folk version" whereby "someone who is "foreign looking' or non-white" (Han, 2012, p. 136). In this paper, we utilize the folk version, but keep in mind the legal status of study participants because this status undoubtedly shapes their acculturation experiences and selfperceptions. By analyzing how immigration has affected sexual-minority males and thus shaped their learning needs, we aim for adult educators to become further aware of and engage with inclusive teaching practices. We chose to work with persons who possess Middle Eastern backgrounds because of the highly contested religious, political and cultural discourse that perceives homosexuality differently from Western nations. We hope that this paper will provoke a wider interest in examining not only the lives of sexual-minority male immigrants, but also the othered lives of persons who remain on the social periphery and yet have important learning needs to be met.

Learning to navigate a new culture and location is certainly part of the process of integrating within a new country. However, the lives of sexual-minority males are complex, especially in a current era whereby sexual-minority male immigrants (a) are unduly complicated by gay rights ${ }^{3}$, (b) are situated within the numerous cultures to navigate through (e.g., political, ethnic, religious and so forth), and (c) must adhere the variety of laws in place especially those in committed relationships unrecognized in law. Once arrived in the new country, sexual-minority male immigrants may find themselves isolated and disillusioned by a social reality not meeting

\footnotetext{
${ }^{1}$ The term sexual-minorities is defined as people who possess same-gender desires and act on these desires through their practices. The term represents a shift away from the practice of using Western-oriented, identity-generating categories, such as the terms gay men and lesbians, which may be unfamiliar in other cultural contexts.

${ }^{2}$ The distinction and categorization of developed and less developed are problematic terms for a variety of reasons beyond the scope of this paper. We suggest Abdi \& Kapoor (2009) for a more meaningful inquiry into these two concepts within an adult education context.

${ }^{3}$ We remark here that "gay rights" continues to be a Western-oriented, socially constructed phenomena that may not have much relevance outside of Western contexts (Mizzi, 2008).
}

Brock Education, 22 (2), 84-98 
their expectations. With this social reality in mind, the question that guides this inquiry is as follows: What are some of the learning needs Middle Eastern, male, sexual-minority immigrants possess in light of their unique positionalities as immigrants in Canada and the United States? This question reflects on how much of the literature around sexual-minority immigrants contains analyses about their difficult experiences crossing borders in particularly a United States context as well as cultural adjustment issues shaped by racist, homophobic and xenophobic encounters (Mizzi, 2012).

In this paper, we present three cases of male sexual-minority males who have come to the United States and Canada after having being born and raised elsewhere. Through the use of three separate case examples we examine how their lives, goals, and needs are very much constructed differently, despite sharing similar sexuality, gender, ethnic (Arab) and religious (Islam) origins. We begin this discussion with an explanation of the literary background and social context that characterizes the lives of sexual-minority immigrants. Afterwards, we explain our theoretical orientation (Transformative Learning) in which we view this work. We then describe our methodology, present our data and offer an analysis and discussion of the data. A conclusion then summarizes our key points in this paper.

\section{Background and Context}

Very little literature has paid attention to learning needs that are unique to sexual-minority immigrants. Activists and scholars have recently brought forward international awareness on the difficult lifes of sexual-minorities as they cross borders(e.g., Luibhéid, 2004). For example, awareness, and in some cases, conflict, over gay rights in the US has brought heightened concern to sexual-minority communities. In the United States, a patchwork of marriage and domestic partnership laws cause confusion over the actual status of same-gender relationships. Although the uniformity of the same-sex marriage law in Canada has been helpful in this regard, the recently discovered loophole over the inability for foreign same-sex couples to divorce demonstrated once again that same-sex marriage remains a hot-button issue as sexual-minorities became alarmed that the confusion may lead to a complete reversal in law (Hayward, 2012). In both cases, laws remain politicized and, as a result, there is a distinct possibility that both positive and negative change could take place according to different regimes of power. Because of this uncertainty, anxiety over the present and future gains remains a concern for sexualminorities.

Since we are referring to sexual-minorities, it is useful to point out that there is no uniformity when it comes to sociocultural perceptions of homosexuality across the globe (Herdt, 1997). The men participating in this study come from places that generally view homosexuality not in terms of an actual identity per se, but more so as a practice bound by gender roles amidst strict religious conventions. The introduction of sexual "identities" from Western nations has now complicated Islamic perspectives on sexuality. In some places, such as Egypt, engaging with Western sexual categories means that "there is a different level of awareness of wrongdoing when there is a term to describe what exactly is forbidden and consequently, the concealment is different" (Khayatt, 2003, p. 220). The "crime" then, as Dunne (1990) refers to it, occurs when individuals who practice same-sex acts publicly adopt a forbidden homosexual identity, or use the label of a gay identity to further shame or alienate one another. Homosexuality, or claiming a homosexual identity, forms a distinctive type of power relationship that is based on a dominant/subordinate $=$ heterosexual/homosexual binary (Daniel, 1994). 
Sexual categorizations of this kind mean that those persons who engage with cross-sex practices confer dominant power, and thus are considered normal. In contrast, persons who engage with same-sex practices become subversive within social relations. Dialmy (2010) contends that the rejection of homosexuality by Muslim men is heightened in the face of loss of power and prestige in their communities. Given that Muslims have largely been subordinated by Western society, the virulent rejection of homosexuality serves to strengthen masculinity and power in nationalist and religious milieu. The problem then lies with how this rejection of homosexuality has affected Muslim sexual-minority males, even in incidences when they immigrate to another country to "escape" harm. How this rejection shapes learning needs and practices is what we seek to further understand here. With this context in mind, we now turn to transformative learning theory to provide some insight into how to analyze this social phenomenon of crossing borders.

\section{Transformative Learning}

Transformative learning theory, a hallmark of adult education and adult learning, suggests that a particular type of learning occurs during a "disorienting dilemma" (Mezirow, 1978, p. 12). This means that deeply held beliefs and understandings about the physical and social dimensions are reshaped to reflect current experiences and dilemmas. Sometimes this experience can be disorienting to learners, which responsibilitizes educators to effectively assist their learners through their dilemmas. Mezirow's conception of transformative learning involves a step-wise process of critical thinking and transformation that affects the frame of reference (Dirkx, Mezirow,\& Cranton, 2006). Mezirow's steps (Dirkx et al., 2006, p. 124) involve:

1. Recognition that an alternative way of understanding may provide new insights into a problem;

2. Context awareness of the sources, nature, and consequences of an established belief;

3. Critical reflection of the established belief's supporting epistemic assumptions;

4. Validating a new belief by an empirical test of the truth of its claims, when feasible, or by a broad-based, continuing, discursive assessment of its justification to arrive at a tentative best judgment;

5. Coping with anxiety over the consequences of taking action;

6. And taking reflection action on the validated belief.

With these points in mind, we observe that practical reasoning is the major tool that leads to perspective change as part of transformative learning. We also observe how Mezirow's work has been characterized as being overly technical-rational and linear in nature, and does not reflect on the actual nature of perspective change (Baumgartner, 2012).

Dirkx, another significant transformative learning theorist, communicates that transformative learning is "inner work" or "soul work" (Dirkx et al., 2006, p. 125). Dirkx claims that transformative learning is more than a technical-rational process, and focuses on challenges 
to "existing, taken-for-granted assumptions, notions, and meanings" (p. 126) as part of his reconceptualization. The result is a change in awareness of the inner self and a change in identity. The goal of transformative learning for Dirkx is the bringing together of the self and society such that "authenticity" can be achieved in thought and being. Dirkx contends that, and perhaps most an important aspect to our work, transformative learning re-shapes inner meanings and expectations through the changes brought on by learning and life experiences.

We understand transformative learning theory to be a useful tool in analyzing and understanding the cases of sexual-minority immigrants from the Middle East given the large cultural differences between the Islamic Arabic world and North America. Re-locating to a new culture as a sexual-minority provides enough dissonance for the technical-rational shift in perspective advocated by Mezirow's transformative learning approach and the inner change and identity work advocated by Dirkx. Transformative learning theory has been used to describe and understand a number of learning projects in which an individual moves from a more familiar context to one that is less familiar. It is through this transformative process that meaning making takes place, which makes learning both dynamic and responsive to individual needs. We argue that transformative learning as described by Mezirow and Dirkx becomes a useful tool for understanding meaning making by the study participants. For example, Eichler (2010) highlights the stories of heterosexual/straight-identified ally activists of LGBTQ people in a United States context who embody the inner change work advocated by Dirkx's perspective so that they can come to understand and appreciate sexual-difference.

\section{Method}

Case study methodology was chosen because its ability to "investigate complex social units consisting of multiple variables of potential importance in understanding the phenomenon" (Merriam, 2001, p. 41). Although case studies do not provide for more traditional generalizability to populations that studies of a quantitative nature provide, they do offer generalizability to theory as well as knowledge and practice development within the field (Anthony \& Jack, 2009; Flyvbjerg, 2011).

We set out to develop an understanding of the phenomenon of sexual-minority males from the Middle East who immigrate to the United States and Canada and in doing so, decided on a multiple case study approach. According to Stake (2005), multiple case studies are of great use in investigating a "phenomenon, population, or general condition" (p. 445). The cases are not selected to represent the phenomenon as a whole, but rather to provide the potential for understanding the complexity of the phenomenon. The potential for learning about a particular phenomenon is a key criterion to the selection of the cases in a multiple case study. Each of the three individuals presented here as cases represents a unit of analysis. Our goal is not to produce an analysis suitable for generalization to the entire class of sexual-minority males in similar situations. Rather, we seek to unravel the complexity and demystify the process of crossing borders for sexual-minority males. We also selected our cases, which are at the individual level, with our own intrinsic interests in mind. As researchers, educators, activists, and social beings, we had a sense of the complexity that characterizes the lives of these men.

In this paper we present three case studies of sexual-minority males: (a) one Canadian, who is originally from Jordan, (b) one American, who is originally from Iraq and (c) a temporary worker from Saudi Arabia who is based in Canada and hopes of, as he says, "receiving a Canadian passport" in years to come. Each participant identifies as Muslim, but their 
commitment to Islam varies according to the participant. We offer these three case examples because they share a regional Middle Eastern and Muslim background, and yet chose to re-locate to two different countries and diverse paths. In our view, this dual perspective informs some of the differences in learning needs. We present these cases in a case-by-case manner to preserve the complexity and wholeness of the stories of these men (Yin, 2012).

As researchers and educators, as well as men who identify as sexual-minorities, we have become involved in research around sexual-minorities through our own curiosity about reading the complications of the lives of sexual minorities. Robert, a Canadian, has extensive international experience working and living in several countries, including several Muslimoriented nations, and focuses his research interests on sexual-minorities who cross borders. Matthew, an American, has worked with international students, and has numerous refugee, asylee, and immigrant friends and colleagues. Both authors are aware of the political and social implications of working as white, sexual-minority, North America-born men conducting research in intercultural settings and, as a result, approach our personal and professional interests with a great deal of sensitivity and care.

We chose in-depth interviews as the technique to facilitate data collection. Some researchers consider interviews with human subjects as being core to any qualitative fieldwork (Lichtman, 2010). Through the use of in-depth interviews, a researcher obtains greater insight into the human experiences that make up the social phenomenon being researched. In-depth interviews can be structured as an informal dialogue between the interviewer and the study participant (Lichtman, 2010). In-depth interviews, according to Lichtman (2010):

Hear what the participant has to say in his own words, in his voice, with his language and narrative. In this way, participants can share what they know and have learned and can add a dimension to our understanding of the situation that questionnaire data or a highlystructured interview does not reveal. (p. 143)

Questions, then, act as a "flexible checklist or guide" that invites a greater emphasis on study participants' voice in relation to interview topics (Lichtman, 2010).

Data collection and analysis occur simultaneously, both in and out of the field (Merriam, 2001). After in-depth interviews, the authors record their thoughts in memos and descriptive notes as well as short exchanges to one another through e-mail. Because the authors conducted the project together in disparate and separate locations, authors communicated and co-analyzed the data utilizing Web-based technology to exchange impressions, thought, and direction as they continued to refine their data collection. Each author provided the knowledge of one case and did the subsequent interviewing. All names and other identity-markers have been changed protect anonymity.

\section{Presenting the Data}

\section{Adnan's Story}

Jordan, like other places in the Middle East, remains an uneasy and conflicted place to live for sexual-minority males. For Adnan, who was "itching for something different", the promise of a more free nation that accepts homosexuality indeed inspired the possibility to live an open life without much complication around being a sexual-minority. Yet, arriving in 
Toronto, Canada five months after 9/11 demonstrated that even free nations like Canada held deep racist perspectives toward people with Middle Eastern backgrounds.

Adnan reflectively questions, "How do I fit in North America? How do I accept my life being in North America with all of this around me, and what to do about it?" Committed to a better life for himself and for folks with similar backgrounds, Adnan began teaching adults, such as social service providers, about Islam and sexuality, Middle Eastern sociocultural backgrounds, and newcomer sexual-minority populations. Part of the job adjustment meant coming to understand, communicate, and blend Canadian and Arab perspectives on sexuality in certain work and life situations. For instance, participating in a pride parade was an experience that was "very overwhelming to say when you're a gay Muslim or Arab, and have a flag and everybody is cheering for you and all this stuff with these straight people and families. I didn't get it."

It was moments like this one that began to complicate notions of sexuality for Adnan. Although he learned of pride parades taking place in the West while living in Amman, he didn't expect to experience the barrage of emotions associated with the event. When reflecting on the gay and lesbian community in Toronto, he adds:

It took me a while to really realize that this is not who I am, that regardless of who I am attracted to, I don't think I'm 'gay' which is Church Street ${ }^{4}$, which is Will \& Grace 5 , which is Queer as Folk ${ }^{6}$. That's not me at all. That is a very specific term in English to describe a certain culture - Western culture - and certain places of Western culture that doesn't really speak to my history and my background, who I am, who I want to be and how I want to behave.

With this in mind, Adnan's learning needs seem focused on negotiating a sense of self amidst a Western perspective of sexuality and how to blend these perspectives. He concludes:

So I think actually my views on sexuality might be a bit more controversial, especially, for example, when I worked on some projects around sexual health and HIV/AIDS when we'd talk about - like I would talk about gay men or MSM and men having sex with men, or we would talk about other identities that include people that come from different cultures and move around the world differently and have sexual encounters differently and all that stuff.

It is through this adult-teaching work that Adnan balances his cultural knowledge obtained from his Jordanian background and his present work/life situation in Toronto, and that this cultural work leads his learning journey.

\section{Ali's Story}

Life for sexual-minority males in Iraq is rather complicated. On one hand, same-gender sexual activity is known to exist; yet on the other, it is not spoken about except in the most derogatory of terms. Further, extensive family and tribal systems keep sons and daughters living with their parents until marriage, preventing sexual-minority couples from cohabitating together. Same-

\footnotetext{
${ }^{4}$ One of the "gay and lesbian" villages in Toronto, Canada.

${ }^{5}$ This is a popular American television series that depicts the lives of American gay men.

${ }^{6}$ Largely filmed in Toronto, this is a popular American television series that depicts the lives of American gay men.
}

Brock Education, 22 (2), 84-98 
gender sexual activity is frowned upon by all major religious, tribal, and racial groups in Iraq. Honour killings are practiced in some areas for those known to participate in out-of-marriage sexual activity.

When Ali was asked about coming to the United States, he states that he had the idea to come to the United States when he was in kindergarten, far before he realized his homosexuality. He states, "I didn't come here because I'm gay" several times throughout the interviews. "Your story should be about someone who is unhappy about being gay and comes here. What you are writing is not good. I didn't come here because I was gay," he argues. Although it is his insistence that he did not come to the United States because he is a sexual-minority, he did seem to come for greater opportunity, which he later admits was at least a little about his sexualminority status. At the time of writing, Ali had been in the United States for just over two years. Ali became interested in coming to the United States as a child when he saw footage of the United States Space Program, and envisioned himself as a future astronaut. "They [the United States] seemed to have everything. They seemed to have all the food, all the kids could travel to space." Having grown up under the embargos in Iraq, Ali was used to having very little material or financial wealth.

Ali's dream was to pursue a scientific or engineering career in the United States. $\mathrm{He}$ completed an engineering degree in Iraq as the Saddam Hussein's Baathist regime was falling apart. After completing the degree, he became aware of the opportunity to work for the US Army as a translator. During his time working with the United States Army, he was heckled by the soldiers; recounting one time in particular where a number of soldiers pulled out their genitals and wanted him to perform oral sex on them. In order to avoid some of this harassment, Ali and another translator, a woman, developed a system, where she would claim to be his girlfriend, and he would find her customers for her illicit and growing prostitution business on the United States base. Ali smuggled items into the military base, particularly anabolic steroids, to a United States Soldier who promised he and Ali would be a couple in the United States. Ali took great delight in having found a husband, even though both men kept this secret. After Ali discontinued his service as a translator, which cut off the steroid supply, the soldier would not respond to calls from Ali.

After having arrived in the United States, Ali had a difficult time finding what he considered high-quality men for dating and friendship, relying mainly on online chat rooms and match-up websites. He had problems relating to the small Iraqi community in his city, especially because the other Iraqi men found his sexual orientation unacceptable. He was left trying to bridge two social groups related to his identity as an Iraqi sexual-minority male. Few American men seemed to want to be friends or date because of his seemingly strange accent, culture, and their own xenophobic values towards outsiders. He had a few part-time jobs, but was eventually laid off over time. Ali is largely disillusioned by his experience in the United States, both in terms of meeting potential partners and in terms of his meeting his professional goals. He states,

I had a fake dream. It's not the 'Promised Land' I dreamed of. Like, no jobs, with all my skills. My degree is nothing. ... I'm always under the spotlight for being Arabic, and I'm always suspect for being a terrorist. Plus my last name is [a common Arabic name] and that makes things harder.

Ali does have a boyfriend he has lived with for almost two years. Although he was prepared to be a professional engineer in Iraq, in the United States he has had to take up studying

Brock Education, 22 (2), 84-98 
a second bachelor's degree because his Iraqi degree is not acknowledged among the engineering field in the United States. He continues to grapple with the notion that "homosexuals are at the bottom" in Iraqi society and relates his unmet expectations and limited success in the United States to this belief.

\section{Murad's Story}

By the age of 14, Murad had already secretly developed sexual relations with other men, enjoyed American, queer, pop culture, and involved himself in the underground sexual-minority scene in Riyadh, Saudi Arabia. He explains:

From my age of 16-18, we were safe. Nobody knew what gay meant. We had our cafés, and our parties and it was fine. After I left in 2006, society for many different reasons including a vocalization of being queer from the West, the government started to react and acknowledge that we exist. That wasn't a good thing because since then I've witnessed every gay Saudi friend get arrested.

Given that Saudi Arabia considers homosexuality a crime, Murad, who enjoys disturbing male gender roles through, for example, wearing make-up, needed to live in a city where it is safe for differently gendered individuals. In his view, living in such a city is important if he is going to maintain a trajectory of personal and professional success.

At age 18, Murad never expected to head to Canada for school or work. Members of his family already had a long tradition of visiting and studying in the United States, and then returning back to Saudi Arabia after their degrees were completed. After receiving a suggestion from his father to study in Canada and not the United States due to the post-9/11 backlash against Muslims and cutbacks in the government scholarship schemes to the United States, Murad first looked online for information. His first act was not to examine the visa requirements for Saudi nationals to study in Canada, probe how Islam-friendly Canada was, or what kind of schools were available to him. Instead, Murad looked up what sexual-minority life was like in Canada, and specifically chose Toronto for its characterization as, in his words, a "gay heaven" and because Toronto was the setting for Queer as Folk, which he used to watch with his friends while living in Riyadh. But safety against sexual persecution was not the only impetus for Murad's transition to Canada. Murad also required a space that was friendly to Middle Eastern people in a post-9/11 world. When he began school at a Canadian university in Toronto, he began to learn about Canada's multicultural identity and how racial minorities come to terms with living in a "plural" society. Although he observed how every nation in the world seems to be represented in Toronto, he shares:

It is very racist here, but not as bad as the southern states in the United States or Australia. There is that facade of everyone living together and at the end of the day I've had so many friends, including myself, trying to find jobs who struggle because of their associations. I have friends who change their name to a 'white' name, and then they finally would get callbacks. I have had to learn how to adapt as well.

In addition to this point, when asked about what would have helped him adjust to Canada, he comments how he realized beforehand that Canada was "gay-friendly", but he too felt the 
overwhelming nature of pride. "It was exhausting mentally, but it was fantastic," he shares. Yet, reflecting on the diversity within pride, he comments how he did not fully realize the amount of racism and sexism within Canadian, sexual-minority culture. He describes that he has "lost faith now in the movement" because Canadian sexual-minority groups have not come to the realization that sexuality and masculinity is understood differently in other cultures. Continuing to use Queer as Folk as his acculturation guide, he has re-viewed the television series since relocating to Toronto and now noted the "problematic" nature of the program and the social "familiarities" of the setting. Murad explains: "In the gay community, masculinity is seen as most valuable and attractive, which I find myself sexually subscribing to. I find this problematic and I need to check myself."

Last, Murad comments how he learned of the social services in Canada when his Somalian friend was kicked out of his house for being gay. He explains:

I was with him throughout the process. It was right after I got here and it was fascinating to see all the resources and community organizations and everything. He did not know what to do. I was thinking that if this happens in Saudi, no one is going to give a shit. But I noticed how there are gay community centres here and there are gay rights and no one is prepared to do anything for this kid. That was a wake-up call: the 'gay heaven' is not ready for kids who get kicked out of their homes but, oddly enough, it is ready to organize weddings.

For Murad, it becomes a matter of balancing expectations when crossing borders and not to assume that a "gay community" is very affirming or accepting of social difference.

\section{Analysis and Discussion}

In our view, the concept of learning needs stem from a need for development. The goal of identifying learning needs is to improve upon skills and knowledge that meets a specific purpose. Immigrant sexual-minority males learn the kinds of new knowledge that are necessary to assist immigrants with acculturation and adjustment to a new work-life situation. In this work we have observed that although homosexuality and the Middle East have an uneasy relationship, there is a definite articulation of same-sex desire in the region that is incongruent with Western values around sexuality-difference. This data presented in this paper points out how this tension creates specific learning needs for male sexual-minority immigrants from the Middle East. More specifically, the cases presented in this paper suggest a negotiator imperative, which observes and interprets phenomena through cultural lenses most familiar to the study participant, and, significantly, learn of ways to negotiate through strange and unusual encounters, such as pride parades. This imperative calls upon each participant to work through their foreign experiences on their own and without guidance or facilitation. We frame the analysis of these cases around three time stages of their experiences, (a) Experiences in Home Countries, (b) Initial Experiences in North America, and (c) Transformation. 


\section{Experiences in Home Countries}

All three men were seeking something different in their quest to immigrate to Canada or the US. More specifically, Adnan sought a freer place that openly accepts homosexuality, Ali sought greater opportunity for career and personal advancement, and Murad chose Canada (Toronto in particular) because of the sexual-minority and Muslim-friendly metropolitan life offered. As outsiders looking in from the Middle East, North America painted a falsely rosy picture through discourses such as pop culture or human rights campaigns.

\section{Initial Experiences in North America}

Once landed, however, each of the three participants struggled with how their sexualminority, Arab, Muslim identity fits into North American society. Racialized experiences such as these ones are not new in the literature. Jasbir Puar (2007), who writes on the topic of homonationalism, reflects on how members of the sexual-minority, Sikh community became targets for violence after 9/11. Puar further writes:

It certainly appeared to be the case that our queer South Asian communities were doubly vulnerable to these attacks, especially those more conspicuously marked by visible traits associated with gender nonnormativity, working-class and working-poor backgrounds, and immigrant bodies and speech. Some of those assaulted encountered very specific references to faggotry or other homophobic slurs. (p. 168-9)

On one hand, for some sexual-minority men, such as those referenced in Puar's work, integration becomes a test for survival. Yet, on the other hand, some sexual-minority men, such as Adnan, Ali, and Murad, these tests begin to carve out a specific set of learning needs. For instance, although Adnan felt overwhelmed with a predominantly white, middle-class, gay community, he addressed his learning needs through teaching about Islam to and engaging dialogue with Canadian social service providers. In addition, Ali's experience speaks more so to his personal and professional need to work in his preferred field. Murad's experience provides another perspective, whereby there are social and educational circumstances that inform his learning needs of how to navigate through Toronto as a sexual-minority male, an immigrant, and a Muslim.

\section{Transformation}

Although personal differences (e.g., personality, background) certainly shape life directions, perhaps these three situations illustrate the importance of context and its role in reconstructing learning and identity in the new work/life situation. What we mean here is that since Canada, and more specifically, Toronto, has indeed sexual-minority-affirming aspects of sociality, Adnan learned of the possibilities to pursue a work/life path largely unavailable in Jordan and Murad learned of the limitations towards a successful acculturation. In contrast, Ali came to the United States expecting new possibilities of a similar nature, which were largely unmet. He is unable to practice his profession, thus learning the impossibilities in the transition. Although each participant was promised acceptance into their choices, they each felt they were sold false hope. Their learning needs surfaced by understanding what was (not) presented in the 
new work/life scenario, balancing the possibilities, limitations and impossibilities, and coming to grips with social differences before, during and after immigration.

Given the "controversial" nature of homosexuality, this balancing of possibilities, limitations, and impossibilities in the new country further complicates matters for these sexualminority males and reveals multiple, diverse, and conflicting learning needs. For example, Ali's experience with the soldiers while in Iraq sheds light on the ongoing struggles he has within the United States. The soldiers wanting oral sex from Ali can be interpreted as both an individual desire as well as more symbolically as treating Ali as the submissive, domestic, and feminine role in post-war Iraq against their own hyper-masculine, powerful, and wealthy United States. Ali's experience in the United States continues this theme whereby he struggles to find validation and fair treatment through employment, particularly one that utilizes his talents and training in the science and engineering field. Ali's learning needs are complex because his needs are characterized by re-living his past experiences, negotiating through present life circumstances, and carving out a future path for professional success. He realizes the possibilities, limitations, and impossibilities that shape his learning needs.

Ali's story is not alone in the data. Adnan and Murad also balanced possibilities, limitations, and impossibilities as they navigated through life in Canada. Life in Toronto was not a "gay heaven" for ethnic, sexual-minority males and the Canadian study participants needed to re-orientate their learning through their day-to-day life experiences. For example, when Murad learned of what is (not) provided by social service providers in the case of his friend being kicked out of his house, he began to doubt the capability and openness of Canadian agencies to support sexual-minorities. He reflected on this inability as being similar to life for sexualminorities in Saudi Arabia.

In light of the information presented in this study, it becomes clearer to us that the process of identifying learning needs can be just as important as meeting learning needs. Study participants learned from multiple sources and sometimes these sources were inconsistent with social realities and with each other. This inconsistency caused a heightened "disorienting dilemma" during the transformative learning experience that is characterized by an increased sense of confusion, disdain, and betrayal. What ultimately provided some solace for these participants was the development of helpful relationships with individuals from both Western and Middle Eastern backgrounds. These relationships assisted study participants in negotiating difficult encounters and maintaining a trajectory of development.

\section{Conclusion}

This paper introduces some of the difficulties associated with being a sexual-minority male and the act of crossing borders. Through the experiences of three Middle Eastern and Muslim men who immigrated to Canada and the United States, information about learning needs came to light. The three cases provide insight on the way that being sexual-minorities intersect and, at times, trouble heterosexist perceptions of an immigrant identity. These three cases provide three different experiences that reveal possibilities for sexual-minority men immigrating to the United States and Canada. Learning of and contextualizing these experiences provided some clue into how the experiences of immigrants negotiate the context of Canadian and American lives. We understand that the lives and experiences of these men will continue to be enriched by their ongoing learning and identity work. What is clear in the data is that individuals immigrate for a variety of reasons, and in many ways, are left to explore and make sense of their new lives on 
their own. These men live between borders in terms of negotiating the identities associated with being immigrant, the identities that originate from their home cultures, and the requisite identities constructed in American and Canadian life. These lives are especially complex for sexual-minority males because they navigate and explore homosexuality in a location where life is very different in their new context than their former locations. Even though they immigrated for the chance to develop new possibilities, the social reality of immigrant life as a sexualminority man from the Middle East is rather complex and certainly not easy. Their learning journeys are transformative; they face multiple disorienting dilemmas and have to resolve these dilemmas through acquiring new understandings. Through shedding light on the complexity of the life experiences of these men, we hope to show there are unique learning needs to be considered in the planning of educational and social programs.

\section{Acknowledgements}

This paper was presented in an earlier form at the Lesbian, Gay, Bisexual, Transgender, Queer, and Allies Preconference at the Adult Education Research Conference, June 2012, in Saratoga Springs, New York, USA. The authors would like to thank the reviewers and editors for their insightful comments on earlier drafts of this paper. They would also especially like to thank the study participants who graciously volunteered to be a part of this study. 


\section{References}

Abdi, A., \& Kapoor, D. (Eds.). (2009). Global perspectives on adult education. New York, NY: Palgrave MacMillan.

Anthony, S., \& Jack, S. (2009). Qualitative case study methodology in nursing research: An integrative review. Journal of Advanced Nursing, 65(6), 1171-1181.

Baumgartner, L. M. (2012). Mezirow's theory of transformative learning from 1975 to present. In E. W. Taylor et al., (Eds.), The handbook of transformative learning: Theory, research, and practice (pp. 99-115). San Francisco, CA: Jossey-Bass.

Hayward, J. (2012, February 17). Same-sex marriage law change addresses divorce. CBC News. Retrieved from www.cbc.ca.

Daniel, M. (1994). Arab civilization and male love. In J. Goldberg (Ed.), Reclaiming Sodom (pp. 59-65). New York, NY: Routledge.

Dialmy, A. (2010). Sexuality and Islam. The European Journal of Contraception and Reproductive Health Care, 15(3), 160-168.

Dirkx, J. M., Mezirow, J., \& Cranton, P. (2006). Musings and reflections on the meaning, content, and process of transformative learning: A dialogue between John M. Dirkx and Jack Mezirow. Journal of Transformative Education, 4(2), 123-139.

Dunne, B. (1990). Homosexuality in the Middle East: An agenda for historical research. Arab Studies Quarterly, 12(3/4), 1-23.

Eichler, M. A. (2010). Joining the family: Experiences of being and becoming ally activists of LGBTQ people. Journal of Transformative Education, 8(2), 89-102.

Epps, B., Valens, K., \& González, B. (Eds.). (2005). Passing lines: Sexuality and immigration. Boston, MA: Harvard University.

Flyvbjerg, B. (2011). Case study. In N. K. Denzin \& Y. S. Lincoln (Eds.), The Sage handbook of qualitative research (4th ed., pp. 301-316). Los Angeles, CA: Sage.

Han, H. (2012). Being and becoming a 'new immigrant' in Canada: How language matters, or not. Journal of Language, Identity and Education, 11(2), 136-149.

Herdt, G. (1997). Same sex, different cultures: Gays and lesbians across cultures. New York, NY: Westview Press.

Khayatt, D. (2003). Terms of desire: Are there lesbians in Egypt? In R. Bayley \& S. Schecter (Eds.), Language socialization in bilingual and multilingual societies (pp. 218-231). Toronto, Canada: Multilingual Matters. 
Lichtman, M. (2010). Qualitative research in education: A user's guide (Rev. ed.). Thousand Oaks, CA: Sage.

Luibhéid, E. (2004). Heteronormativity and immigration scholarship: A call for change. GLQ: A Journal of Lesbian and Gay Studies, 10(2), 227-235.

Merriam, S. B. (2001). Qualitative research and case study applications in education (Rev. ed). San Francisco, CA: Jossey-Bass.

Mezirow, J. (1978). Education for perspective transformation: Women's re-entry programs in community colleges. New York, NY: Teachers College Press.

Mizzi, R. (2008). Introducing sexual/gender identity themes in emerging nations. In R. Mizzi (Ed.), Breaking free: Sexual diversity and change in emerging nations (pp. 1-11). Toronto, Canada: QPI Publishing.

Mizzi, R. (2012). Sexiles in the classroom: Understanding intersectionalities of sexuality, immigration, and education. In T. Lucas and M. Plathotnik (Eds.), Proceedings of the Florida International University Annual College of Education Graduate Student Network Research Conference (pp. 122-129). Miami, FL: Florida International University.

Puar, J. (2007). Terrorist assemblages: Homonationalism in queer times. Durham, NC: Duke University Press.

Stake, R. E. (2005). Qualitative case studies. In N. K. Denzin \& Y. S. Lincoln (Eds.), The Sage handbook of qualitative research (3rd ed., pp. 443-466). Thousand Oaks, CA: Sage.

Yin, R. K. (2012). Applications of case study research (3rd ed.). Los Angeles, CA: Sage. 